\title{
Subcellular Localization of a Basic Peroxidase Isoenzyme in Crisphead Lettuce
}

\author{
M. Gómez Tena, M.A. Pedreño, A. Ros Barceló ${ }^{1}$, and M.A. Ferrer \\ Department of Plant Biology, University of Murcia, E-30100 Murcia, Spain
}

Additional index words. Lactuca sativa, leaves, protoplasts, vacuoles

\begin{abstract}
The subcellular localization of a basic peroxidase (EC 1.11.1.7) isoenzyme in crisphead lettuce (Lactuca sativa L.) leaves was studied through subcellular fractionation and protoplast and vacuole isolation. This isoenzyme is mainly located in soluble fractions. Studies using protoplast isolation and vacuole purification indicated that the soluble basic peroxidase isoenzyme is found in the vacuolar sap, probably in equilibrium with the same isoenzyme attached to tonoplast membranes.
\end{abstract}

Russet spotting is a postharvest disorder that can develop during transport and storage of crisphead lettuce (Ke and Saltveit, 1989). This disorder is characterized by the appearance of many small brown spots along both sides of the mibrid, spots that can spread over the leaf blade (Link and Gardner, 1919). Peroxidase (EC 1.11.1.7) is an enzyme that may be crucial in this postharvest disorder due to its known participation in oxidative metabolism during plant storage (Frenkel, 1979) and its role in indole-3-acetic acid (IAA) homeostasis through catabolism (Ros Barceló and Muñoz, 1992). Ke and Saltveit (1988) reported that applying IAA greatly reduced russet spotting and IAA oxidase activities and that lignifying russet spotting-affected cells resulted in cell-wall thickening.

IAA oxidase activity resides mainly in peroxidase isoenzymes of the most basic isoelectric point (pI) (Ros Barceló and Muñoz, 1992), and the expression of these isoenzymes is largely regulated by IAA concentrations in plant tissues (Ferrer et al.,1991). These basic peroxidase isoenzymes also play a role in flavonol turnover (Morales et al., 1993b) and lignin biosynthesis (Morales et al., 1993a). We studied the subcellular localization of a basic peroxidase isoenzymes in 1-month-old crisphead lettuce leaves, in which peroxidase polymorphism is mainly restricted to a sole gene product.

\section{Materials and Methods}

Chemicals. Caylase was purchased from Cayla (Toulouse, France), pectinase from Serva (Heidelberg, Germany), and pectolyase Y-23 from Seishin Pharmaceutical Co. (Tokyo). All other chemicals were obtained from Sigma Chemical Co. (Madrid, Spain).

Plant material. 'Nordic Grande' crisphead lettuce seeds were sown in vermiculite in plastic trays. The trays were placed in a growth chamber with an 18-h light and 6-h dark photoperiod at $25 \mathrm{C}$. Light was provided at $\approx 80 \mu \mathrm{mol} \cdot \mathrm{s}^{-1} \cdot \mathrm{m}^{-2}$ by cool-white fluorescent tubes. Water and fertilizers (crone medium) (Hewitt, 1966) were periodically supplied during the 1-month growing period.

Tissue and peroxidase preparation. Ten grams of leaf tissue was homogenized at $4 \mathrm{C}$ with a mortar and pestle in $10 \mathrm{ml}$ of 0.25 M sucrose, $1.0 \mathrm{~mm} \mathrm{Mg}$ acetate, and $50 \mathrm{~mm}$ tris- $\mathrm{HCl}$ buffer, $\mathrm{pH} 7.5$. The homogenate was immediately squeezed through one layer of cellulose gauze $(0.2-\mathrm{mm}$ mesh) and centrifuged at $1000 \times g$ for 5

Received for publication 1 Feb. 1994. Accepted for publication 14 June 1994. This work was supported, in part, by a grant from the CICYT (Spain), project no. ALI 573/93. The cost of publishing this paper was defrayed in part by the payment of page charges. Under postal regulations, this paper therefore must be hereby marked advertisement solely to indicate this fact.

${ }^{1}$ To whom reprint requests should be addressed. min. Soluble, membrane, and cell-wall fractions were prepared as described by Ros Barceló et al. (1989).

Ionically bound cell-wall peroxidases were removed from the purified cell-wall pellet according to the method of Ros Barceló et al. (1987). Membrane-bound peroxidase was solubilized as described by Ros Barceló et al. (1988). All peroxidase fractions were dialyzed overnight against $50 \mathrm{~mm}$ tris- $\mathrm{HCl}$ buffer, $\mathrm{pH}$ 7.5.

Mesophyll protoplast isolation. The lower epidermis of $1.0 \mathrm{~g}$ of leaf tissue was removed with tweezers and immersed in $20 \mathrm{~mm}$ trismes buffer, $\mathrm{pH} 5.5$, containing $1.0 \mathrm{mM} \mathrm{CaCl}_{2} 1.0 \%$ (w/v) bovine serum albumin (BSA), and $0.65 \mathrm{M}$ sorbitol to prevent tissue dehydration. The leaves were incubated in a maceration medium $(25 \mathrm{ml})$ containing $1 \%(\mathrm{w} / \mathrm{v})$ caylase, $0.02 \%(\mathrm{w} / \mathrm{v})$ pectolyase, $0.2 \%\left(\mathrm{w} / \mathrm{v}\right.$ ) pectinase, $1.0 \%(\mathrm{w} / \mathrm{v}) \mathrm{BSA}, 1.0 \mathrm{~mm} \mathrm{CaCl}_{2}$, and $0.65 \mathrm{~m}$ sorbitol in $20 \mathrm{~mm}$ tris-mes, $\mathrm{pH} 5.5$, at room temperature for $45 \mathrm{~min}$ in darkness with occasional stirring. The released protoplasts were filtered through nylon gauze $(40-\mu \mathrm{M}$ mesh), centrifuged at $100 \times g$ for $6 \mathrm{~min}$, and washed three times by resuspension in a washing buffer containing $1.0 \mathrm{~mm} \mathrm{CaCl}_{2}$ and $0.65 \mathrm{~m}$ sorbitol in $20 \mathrm{~mm}$ trismes, $\mathrm{pH}$ 7.3. The green precipitate was recovered by suction and viewed under a light microscope $(400 \times)$ to check protoplast integrity and purity. To determine enzyme activities, mesophyll protoplasts were broken by freezing and thawing, then incubated in $1 \mathrm{M} \mathrm{KCl}$ for $30 \mathrm{~min}$ and centrifuged at $15,000 \times g$ for $15 \mathrm{~min}$. The supernatant was desalted by dialysis.

Vacuole isolation. Vacuoles were prepared from mesophyll protoplasts according to the method of Renaudin et al. (1986) but with minor modifications: $0.5 \mathrm{ml}$ of protoplast suspension was added to $0.88 \mathrm{ml}$ of $10 \mathrm{~mm}$ tris-mes, $\mathrm{pH} 7.3$, containing $7.9 \mathrm{~mm} \mathrm{Na}_{2}$ EDTA. After $10 \mathrm{~min}$ at $4 \mathrm{C}$ and gentle shaking, the suspension was quickly mixed with $5.0 \mathrm{ml}$ of $5 \mathrm{~mm} \mathrm{Na}_{2}$ EDTA, $0.36 \mathrm{M}$ sorbitol, and $8.5 \%$ (w/v) nycodenz [5-( $N$-2,3-dihydroxypropylacetamido)-2,4,6triiodo- $N, N$ '-bis(2,3-dihydroxypropyl)isophtalamide] in $10 \mathrm{~mm}$ tris-mes, $\mathrm{pH}$ 7.3. Mesophyll vacuoles were purified by flotation and recovered in the uppermost layer $(0.7 \mathrm{ml})$ after centrifugation at $160 \times g$ for $6 \mathrm{~min}$ at $4 \mathrm{C}$. Vacuole integrity was checked by staining with $1 \%(\mathrm{w} / \mathrm{v})$ neutral red in $0.65 \mathrm{~m}$ sorbitol and $10 \mathrm{~mm}$ trismes, $\mathrm{pH}$ 7.3. To determine enzyme activities, mesophyll vacuoles were broken by freezing and thawing, incubated with $1 \mathrm{M} \mathrm{KCl}$ for $30 \mathrm{~min}$, and centrifuged at $15,000 \times g$ for $5 \mathrm{~min}$. The supernatant was desalted by dialysis.

Enzyme activity measurement. Peroxidase activity was determined at $25 \mathrm{C}$ with 4-methoxy- $\alpha$-naphthol as the substrate according to Ferrer et al. (1990). $\alpha$-Mannosidase (EC 3.2.1.24), a vacuolar sap marker, was measured as reported by Ros Barceló et al. (1991). Enzyme activities, expressed as moles per second (1 $\mathrm{mol} \cdot \mathrm{s}^{-1}=1 \mathrm{katal}$ ) for all the assayed enzymes.

Isoelectric focusing and isoenzyme staining. Isoelectric focus- 


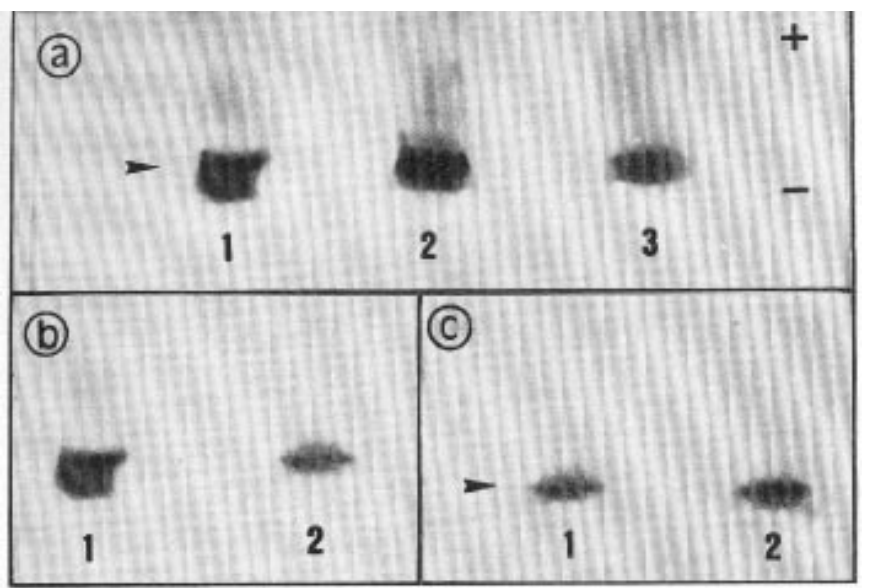

Fig. 1. (a) Peroxidase isoenzyme patterns of soluble (lane 1), membrane-bound (lane 2), and ionically bound cell wall (lane 3 ) peroxidase activity extracted from crisphead lettuce leaves. (b) Isoenzyme patterns of lettuce peroxidase activity of soluble fractions (lane 1) and of mesophyll protoplasts (lane 2). (c) Isoenzyme patterns of peroxidase activity in the starting mesophyll protoplasts (lane 1) and vacuoles (lane 2) of lettuce leaves. ing and peroxidase isoenzyme staining with 4-methoxy- $\alpha$-naphthol were carried out according to Calderón et al. (1990) and Ferrer et al. (1990), respectively.

\section{Results and Discussion}

Subcellular fractionation of crisphead lettuce leaves revealed that most of the peroxidase activity measured, with 4-methoxy- $\alpha$ naphthol as the substrate, was localized in the soluble (nonsedi-

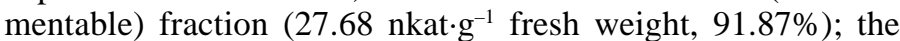
remaining activity was associated ionically with cell-wall $(0.07$ nkat. $\mathrm{g}^{-1}$ fresh weight, $\left.0.24 \%\right)$ and the membrane fractions $(2.37$ nkat $\cdot \mathrm{g}^{-1}$ fresh weight, $7.89 \%$ ).

The isoenzyme patterns of soluble, membrane-bound and ionically bound cell-wall peroxidases were analyzed by protein isoelectric focusing in 3.5 to $10.0 \mathrm{pH}$ gradients and staining with 4-methoxy- $\alpha$ naphthol as the substrate. Staining revealed the presence of only one strongly basic ( $\mathrm{pI}>9.0$, cationic) peroxidase isoenzyme in all subcellular fractions (Fig. 1a). No acidic (anionic, pI < 7.0) peroxidase isoenzymes were present in any subcellular fractions.

Since the soluble fraction contained the most peroxidase activity $(\approx 92 \%)$ and basic peroxidase isoenzyme, this fraction was used for
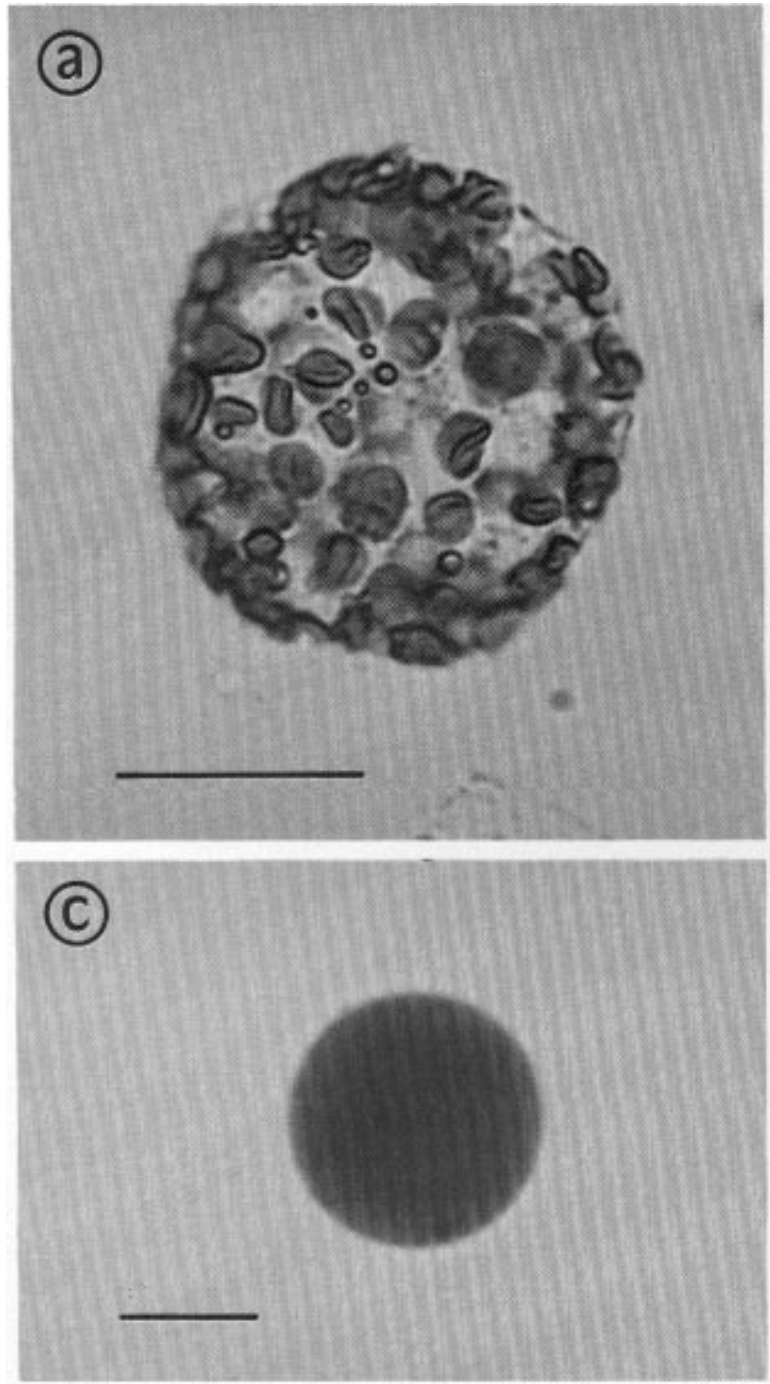

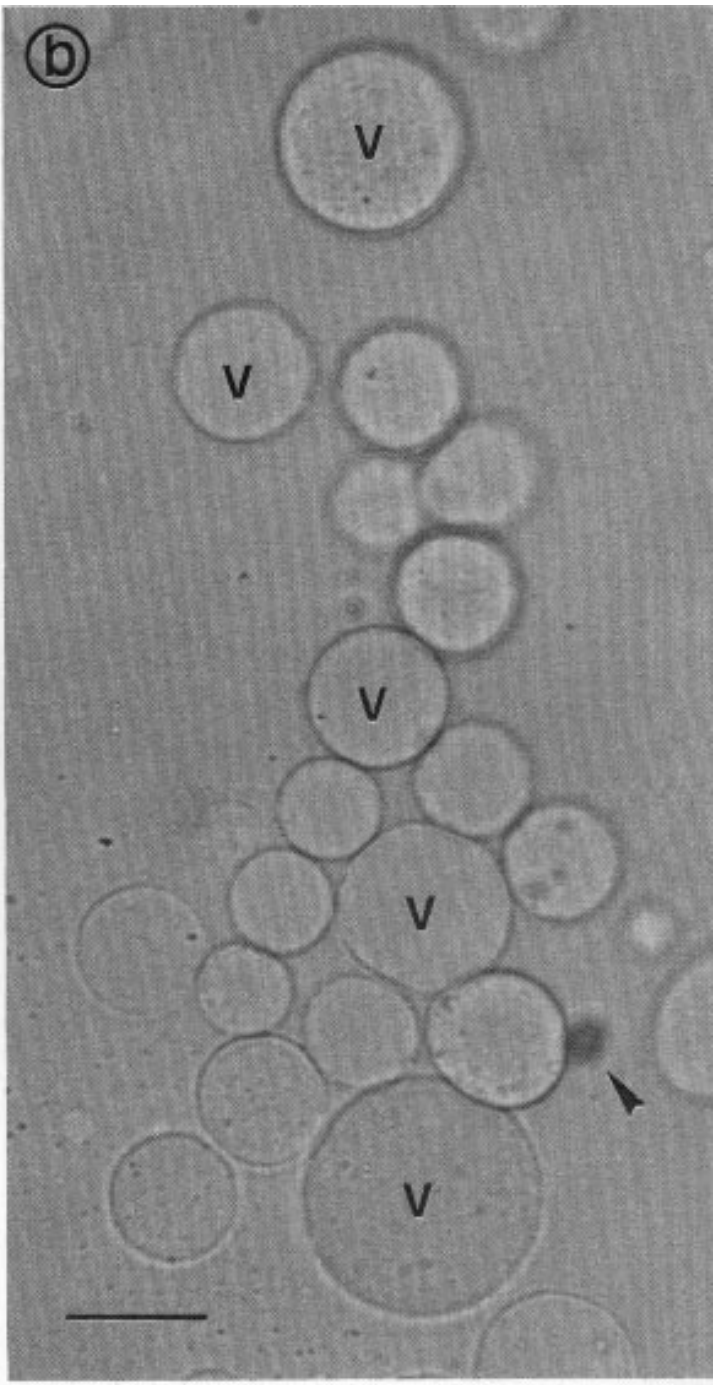

Fig. 2. (a) High magnification view of a crisphead lettuce mesophyll protoplast (bar $=15 \mu \mathrm{m}$ ). (b) Vacuoles (v) found in the uppermost layer of the nycodenz gradients used for vacuole purification by flotation showing trace contamination by chloroplasts (arrowheads) $(b a r=20 \mu \mathrm{m})$. (c) Light micrograph of a lettuce vacuole stained with neutral red $(\mathrm{bar}=20 \mu \mathrm{m})$. 
further studies concerning subcellular localization of peroxidase isoenzyme in lettuce leaves. The nature of intracellular (protoplast) peroxidase activity in lettuce leaves was established by protoplast isolation. Under a light microscope, lettuce protoplasts appeared as spherical naked cells with no apparent membrane damage or disintegration of the internal structure (Fig. 2a). After isoelectric focusing, the peroxidase activity associated with mesophyll protoplasts revealed the presence of a single basic peroxidase isoenzyme (Fig. 1b, lane 2).

To clarify the localization within the protoplast of this strong basic peroxidase isoenzyme, vacuoles were prepared from mesophyll protoplasts through osmotic shock and purified in a nycodenz gradient by flotation. Vacuole purity was checked by light microscopy, and the final vacuole preparations showed no protoplasts and only slight chloroplast contamination (Fig. 2b, arrowheads). High magnification revealed that no membranes adhered to the tonoplast. Vacuole integrity was also checked by staining with neutral red. The results (red-pigmented vacuoles, Fig. 2c) showed that isolated vacuoles retained the $\mathrm{H}^{+}$-transmembrane gradient responsible for the accumulation of neutral red.

Peroxidase compartmentalization in lettuce vacuoles was calculated assuming $\alpha$-mannosidase to be $100 \%$ vacuolar (Wagner, $1985)$. Using this marker, we found that only $28 \%$ of mesophyll protoplast peroxidase was vacuolar. However, this value should be regarded with caution because, although mean values for mesophyll vacuolar $\alpha$-mannosidase are near $100 \%$, they can fluctuate from $47 \%$ to $130 \%$ (Wagner, 1985).

The isoenzyme patterns of vacuolar peroxidase activity (Fig. 1c, lane 2) were similar to those found in the starting protoplasts (Fig. 1c, lane 1), a result suggesting that the mesophyll protoplast basic peroxidase isoenzyme was partly located in the vacuolar sap.

Likewise, the presence of the basic peroxidase isoenzyme in the vacuolar sap (Fig. 1c, lane 2) and in the fraction ionically bound to membranes (Fig. 1a, lane 2) suggests that this isoenzyme may moves freely in the vacuolar sap, probably in equilibrium with the enzyme that is ionically bound to the tonoplast. As has been previously suggested for its homologous basic peroxidase isoenzyme in other plant species, this equilibrium may be controlled by $\mathrm{Ca}^{2+}$ (García-Florenciano et al., 1991 and Ros Barceló et al., 1991).

\section{Literature Cited}

Calderón, A.A., M.A. Pedreño, A. Ros Barceló, and R. Muñoz. 1990. Zymographic screening of plant peroxidase isoenzymes oxidizing 4hydroxystilbenes. Electrophoresis 11:507-508.

Ferrer, M.A., A.A. Calderón, R. Muñoz, and A. Ros Barceló. 1990. 4-Methoxy$\alpha$-naphthol as a specific substrate for kinetic, zymographic and cytochemical studies on plant peroxidase activities. Phytochem. Anal. 1:63-69.
Ferrer, M.A., M.A. Pedreño, R. Muñoz, and A. Ros Barceló. 1991. Soluble peroxidase gradients in lupin hypocotyls and the control of the level of polarly transported indole-3yl-acetic acid. J. Plant Growth Regulat. 10:139-146.

Frenkel, C. 1979. Role of oxidative metabolism in the onset of senescence in plant storage. Z. Ernährungswiss. 18:209-212.

García-Florenciano, E., A.A. Calderón, R. Muñoz, and A. Ros Barceló. 1992. The decarboxylative pathway of indole-3-acetic acid catabolism is not functional in grapevine protoplasts. J. Expt. Bot. 43:715-721.

García-Florenciano, E., A.A. Calderón, M.A. Pedreño, R. Muñoz, and A. Ros Barceló. 1991. The vacuolar localization of basic isoperoxidases in grapevine suspension cell cultures and its significance in indole-3-acetic acid catabolism. Plant Growth Regulat. 10:125-138.

Hewitt, E.J. 1966. Sand and water culture methods used in the study of plant nutrition. Commonwealth Agr. Bureaux, Farnham Royal, Bucks, England.

Ke, D. and M.E. Saltveit. 1988. Plant hormone interaction and phenolic metabolism in the regulation of russet spotting in iceberg lettuce. Plant Physiol. 88:1136-1140.

Ke, D. and M.E. Saltveit. 1989. Developmental control of russet spotting, phenolic enzymes, and IAA oxidase in cultivars of iceberg lettuce. J. Amer. Soc. Hort. Sci. 114:472-477.

Link, G.K. and M.W. Gardner. 1919. Market diseases of vegetables. Phytopathology 9:497-520.

Morales, M., M.A. Pedreño, R. Muñoz, A. Ros Barceló, and A.A. Calderón. 1993a. Purification and kinetic characterization of a basic peroxidase isoenzyme responsible for lignification in Gamay rouge grape (Vitis vinifera) berries. Food Chem. 48:391-394.

Morales, M., M.A. Pedreño, R. Muñoz, A. Ros Barceló, and A.A. Calderón. 1993b. Oxidation of flavonol and flavonol glycosides by a hypodermal peroxidase isoenzyme from Gamay rouge grape (Vitis vinifera) berries. J. Sci. Food Agr. 62:385-391.

Renaudin, J.P., S.C. Brown, H. Barbier-Brygoo, and J. Guern. 1986. Quantitative characterization of protoplasts and vacuoles from suspension-cultured cells of Catharanthus roseus. Physiol. Plant. 68:695-703.

Ros Barceló, A., M.A. Ferrer, E. García-Florenciano, and R. Muñoz. 1991. The tonoplast localization of two basic isoperoxidases of high $\mathrm{pI}$ in Lupinus. Bot. Acta 104:272-278.

Ros Barceló, A. and R. Muñoz. 1992. Peroxidases:Their role in the control of plant cell growth, p. 71-89. In: H. Greppin, C. Penel, and Th. Gaspar (eds.). Peroxidases 1980-1990: Progress and prospects in biochemistry and physiology. Univ. of Geneva, Switzerland.

Ros Barceló, A., R. Muñoz, and F. Sabater. 1987. Lupin peroxidases. I. Isolation and characterization of cell wall-bound isoperoxidase activity. Physiol. Plant. 71:448-454.

Ros Barceló, A., R. Muñoz, and F. Sabater. 1988. Lupin peroxidases III. Subcellular location of membrane-bound acidic isoperoxidases. Plant Physiol. Biochem. 26:575-583.

Ros Barceló, A., R. Muñoz, and F. Sabater. 1989. Subcellular location of basic and acidic soluble isoperoxidases in Lupinus. Plant Sci. 63:31-38. Wagner, G., 1985. Vacuoles, p. 105-133. In: H.F. Linskens and J.F. Jackson (eds.). Cell components. Springer-Verlag, Berlin. 